\title{
A gas chromatography/mass spectrometry method for the simultaneous analysis of 50 phenols in wastewater using deconvolution technology
}

\author{
ZHONG WenJue ${ }^{1}$, WANG DongHong ${ }^{1}$, XU XiaoWei ${ }^{1}$, WANG Bing Yi ${ }^{1}$, LUO Qian ${ }^{1}$, \\ SENTHIL KUMARAN Satyanarayanan ${ }^{2} \&$ WANG ZiJian ${ }^{1 *}$ \\ ${ }^{1}$ State Key Laboratory of Environmental Aquatic Chemistry, Research Center for Eco-Environmental Sciences, Chinese Academy of Sciences, \\ Beijing 100085, China; \\ ${ }^{2}$ Unit of Toxicology, Bharathiar University, Coimbatore 641046, India
}

Received April 6, 2010; accepted July 13, 2010

\begin{abstract}
Phenolic compounds exist widely in the influents and effluents of sewage treatment plants (STPs) and most are un-regulated. In this study, a gas chromatography-mass spectrometry (GC-MS) method for the simultaneous analysis of 50 phenolic compounds in wastewater was developed. Deconvolution technology was used to identify contaminants that are covered by co-extracted materials. A mass spectral library containing all 50 silylated phenolic compounds was first established and used for deconvolution. Twelve typical phenolic compounds were selected to optimize the sample preparation procedures. Solid-phase extraction using a C18 cartridge coupled with an HLB cartridge was used for pre-concentration and dichloromethane was used for elution. The solutes were derivatized and analyzed by GC-MS. The blank and matrix spike recoveries ranged from $57.46 \%$ to $136.4 \%$ and $47.87 \%$ to $114.8 \%$, respectively. Method detection limits ranged from 3.64 to $97.64 \mathrm{ng} \mathrm{L}^{-1}$. The relative standard deviations of all the recovery experiments were lower than $13.6 \%$. The instrument limits of quantification ranged from 0.7 to $87.7 \mathrm{pg}$. The method has been applied to analyze the influents and effluents of 5 Chinese STPs. Except for regulated phenolic compounds (phenol and 2,4,6-trichlorophenol), three un-regulated phenolic compounds, including 2-chlorophenol, 2,5-dichlorophenol and 2,4-dichloro3 -ethyl-6-nitrophenol were identified in the effluent wastewater. The detected concentrations of un-regulated phenolic compounds could possibly cause environmental effects, indicating that immediate attention is required to prevent complications.
\end{abstract}

identify, quantify, phenolic compounds, deconvolution, wastewater

Citation: Zhong W J, Wang D H, Xu X W, et al. A gas chromatography/mass spectrometry method for the simultaneous analysis of 50 phenols in wastewater using deconvolution technology. Chinese Sci Bull, 2011, 56: 275-284, doi: 10.1007/s11434-010-4266-1

In recent years, increasing attention has been paid to micropollutants in wastewater due to increasing concerns about their potential negative impacts on the environment [1]. Phenolic compounds are known for their high solubility in water, strong reactivity and poor biodegradability [2]. Some phenolic compounds are capable of mimicking or disrupting estrogenic activity because their structures are similar to natural estrogen $[3,4]$. Some chlorophenols have been classified as possible carcinogens by the World Health

*Corresponding author (email: wangzj@ rcees.ac.cn)
Organization (WHO) and the International Agency for Research on Cancers (IARC) [5, 6]. Furthermore, chlorophenols can produce a nasty smell and taste even at a very low concentration [7]. Once introduced into the environment through wastewater, phenolic compounds can pose a threat to animal and vegetable organisms and perhaps also to humans through their toxicity, persistence and bioaccumulative potential [7]. Currently, sewage treatment plants (STPs) focus only on removing regulated phenolic compounds such as phenol, 2,4-dichlorophenol and pentachlorophenol. The occurrence of un-regulated phenolic compounds in waste- 
water does not attract the concern it deserves. However, the occurrence of phenolic compounds in effluents has been well documented, including many un-regulated phenolic compounds such as nonylphenol and octylphenol [8-10]. It is therefore necessary to pay more attention to the occurrence and removal of phenolic compounds in effluents of STPs. In this study, we conducted a broad-spectrum analysis of municipal wastewaters to gain a comprehensive understanding of the concentration range of 50 phenols in influent and effluent wastewaters in Tianjin, China.

Many analytical methods for the detection and quantification of phenolic compounds are based on gas chromatography-mass spectrometry (GC-MS) [11,12]. However, most are focused on only few target compounds. An effective method for identification and quantification of a large number of trace phenolic compounds in wastewater is generally lacking. Retention time locking (RTL) and deconvolution report software (DRS) are new techniques developed to cater to multi-residue analysis. They help identify a large number of target compounds simultaneously, even when they are obscured by co-eluting matrix compounds [13]. Therefore, establishing a method for screening target phenolic compounds from a large number of candidates using DRS and RTL is advisable. Even though DRS can qualify and quantify the compounds listed in libraries, there is currently no specialized library dedicated to phenolic compounds. Moreover, phenolic compounds exist at trace or low concentration levels in water samples, making their detection difficult, so little attention has been paid to them. There is therefore a need to find a suitable sample preparation technique, which allows the separation of phenolic compounds from complicated matrices.

The objective of this study was to develop a method for identification and quantification of phenolic compounds by two aspects. The first was to establish a specialized library completely devoted to derivatized phenolic compounds for screening. The second was to optimize the method for sample preparation. The method was then applied to analyze the influents and effluents of five STPs to demonstrate its feasibility.

\section{Materials and methods}

\subsection{Chemicals and materials}

All phenolic compound standards were purchased from Sigma-Aldrich (St. Louis, MO, USA). Stock solutions for each individual phenolic standard $\left(1 \mathrm{mg} \mathrm{L}^{-1}\right)$ were prepared in $n$-hexane. All solvents [methanol, acetone, n-hexane, methyl-tert-butyl ether (MTBE) and dichloromethane (DCM)] were of pesticide residue grade and were purchased from Mallinckrodt Baker, Inc., (USA). Ultrapure water was generated by the Milli-Q system (Millipore, Bedford, MA, USA). Derivatization reagent N,O-Bis(trimethylsilyl) triflu- oroacetamide (BSTFA) with $1 \%$ trimethylchlorosilane (TMCS) was purchased from Supelco (USA). Two types of solid-phase extraction (SPE) cartridges were used, a C18 cartridge $(500 \mathrm{mg}$ ) was from Supelco (USA) and an Oasis HLB cartridge (500 mg) from Waters (USA).

\subsection{Methodology}

(1) Identification and quantification of phenolic compounds. There are 3 steps to identify phenolic compounds in water: 1) sample preparation; 2) determination by GC-MS; and 3) analysis, based on the library of silylated phenolic compounds, using RTL, GC-MS ChemStation and DRS.

After preparing the samples by the optimized method, the samples were analyzed using GC-MS in scan and selected ion monitoring (SIM) mode using the RTL method. The scan data were analyzed using DRS to identify the compounds in the sample matrices. Combined spectra of samples were analyzed by GC-MS with the library of silylated phenolic compounds, and a contaminant list including all the phenolic compounds was identified using spectral deconvolution technology. The phenolic compounds identified by GC-MS were quantified using the SIM results.

(2) Criteria for selecting target phenolic compounds. The selection of 50 target phenolic compounds was based on following criteria: 1) wide use (the production or requirement or import and export amount of one phenolic compound exceeded $1000 \mathrm{t} \mathrm{y}^{-1}$ ); 2) availability of relevant toxicity data; and 3) availability of a standard.

(3) Procedures for building library. After derivatized by BSTFA with $1 \%$ TMCS, each standard compound was analyzed by GC-MS to obtain their mass spectrogram. A library of silylated phenolic compounds was created as a tab file using Microsoft Excel in which compound name, retention time, target ion, quota ion and abundance ratio of ion of each target compound were recorded. A series of conversions were then carried out to build the library. Details for establishing a library can be found in the Agilent Technical Overview [14].

(4) Optimizing the preparation method. To prepare artificial samples in the laboratory, Milli-Q water samples of $2 \mathrm{~L}$ were spiked by adding a mixture of phenolic compounds (including 12 phenolic compounds) dissolved in methanol to obtain a concentration of $250 \mathrm{ng} \mathrm{L}^{-1}$ for each analyte. All artificial samples were adjusted to $\mathrm{pH}<2$ with $6 \mu \mathrm{mol} \mathrm{L}{ }^{-1}$ hydrochloride buffer, filtered through Millipore glass microfiber filters, preserved in brown glass containers, and processed by solid-phase extraction within $2 \mathrm{~d}$. Samples were enriched by SPE using the C18 cartridge, the HLB cartridge and the C18 cartridge coupled with the HLB cartridge.

For the recovery test, a total of 12 different solvents were tested. Matrix spiked experiments were used to validate the selected optimized elution solvents. 
Derivatization was performed to reduce the polarity of phenolic compounds. All extracts were evaporated under a gentle stream of nitrogen. The dry residues were derivatized by $100 \mu \mathrm{L}$ BSTFA with $1 \%$ TMCS and heated in a heating block at $60^{\circ} \mathrm{C}$ for $2 \mathrm{~h}$ [15]. TMCS can enhance the chemical reactivity of silylating agents. The derivatives were cooled to room temperature and then dissolved with $400 \mu \mathrm{L}$ $n$-hexane to yield the sample solution. The constant volume of solutions was $500 \mu \mathrm{L}$.

\subsection{Water sampling}

Influent and effluent samples used in this study were collected from five STPs located in the Tianjin, China. STP1A, STP2A, STP3A, STP4A, STP5A were influents and STP1B, STP2B, STP3B, STP4B, STP5B were effluents of the five STPs. The treatment process of STP1 is anaerobic/anoxic/oxic $\left(\mathrm{A}^{2} / \mathrm{O}\right)+$ continuous microfiltration $(\mathrm{CMF})$ $+\mathrm{O}_{3}+\mathrm{Cl}_{2}$. The treatment process of STP2 is anoxic/oxic (A/O). STP3 applied a conventional active sludge to treat wastewater. The treatment processes of STP4 and STP5 were hydrolysis acidification-biological filter and hydrolysis acidification + membrane bioreactor $(\mathrm{MBR})+\mathrm{Cl}_{2}$, respectively. Cartridges and elution solvents optimized by recovery experiments were applied to prepare samples. Other procedures were the same as mentioned above.

\subsection{Analytical procedure}

The samples were detected using an Agilent 6890 gas chromatograph equipped with an Agilent MSD 5975 mass spectrometer. A capillary column of $30 \mathrm{~m} \times 0.25 \mathrm{~mm}$ i.d. $0.25 \mu \mathrm{m}$ HP-5 was used. Before analyzing samples, the retention time was locked by changing column pressure using standard samples. A constant pressure model was then used for the entire analysis process. The gas chromatography (GC) oven temperature was programmed from 40 to $300^{\circ} \mathrm{C}$ via a ramp of $10^{\circ} \mathrm{C} \mathrm{min}^{-1}$ and maintained at $40^{\circ} \mathrm{C}$ for $2 \mathrm{~min}$ and at $300^{\circ} \mathrm{C}$ for $15 \mathrm{~min}$. The mass spectrum (MS) was operated in full-scan mode from $\mathrm{m} / \mathrm{z}, 50-700$ for qualitative analysis or selected ion monitoring (SIM) mode for quantitative analysis. The inlet and MS transfer line temperatures were maintained at $250^{\circ} \mathrm{C}$ and the ion source temperature was $300^{\circ} \mathrm{C}$. Sample injection $(1 \mu \mathrm{L})$ was done in splitless mode. The data of GC-MS were analyzed by RTL and DRS (software provided by Agilent). The full-scan spectra data file was transferred to the Automatic Mass Spectral Deconvolution and Identification System (AMDIS), which deconvolutes the spectra and searches for compounds using the deconvoluted full spectra. A normal qualitative and quantitative analysis for target compounds was performed, using the characteristic fragment ions of each compound at the correct retention time.

\section{Results and discussion}

\subsection{Parameters of the library of silylated phenolic compounds}

In this study, a library of 50 silylated phenolic compounds was established. To our knowledge, this is the first time such a library has been established for identifying and quantifying phenolic compounds. The retention time of each target compound, target ions, quota ions and abundance ratios of ions are listed in Table 1. For a compound, the spectrum is inherent in the quadrupole mass spectra. The deconvolution process finds ions whose individual abundances rise and fall together within the spectrum. The result first corrects for the spectral skew that is inherent in quadrupole mass spectra and determines a more accurate apex retention time of each chromatographic peak. Therefore, to build the library, phenolic compounds names, retention times, target ions, quota ions and abundance ratios of ion were necessary. The full-scan was carried out to obtain mass spectra of the silylated phenolic compounds. The above parameters were received from the mass spectra (Table 1). For example, for 2,4,6-TCP, the molecular ion was found at $\mathrm{m} / \mathrm{z}, 268$ (abundance 100\%) corresponding to $\left[\left(\mathrm{CH}_{3}\right)_{3} \mathrm{Si}-\mathrm{O}-\mathrm{C}_{6} \mathrm{H}_{3}-\mathrm{Cl}_{3}\right]^{+}$and ions at $\mathrm{m} / \mathrm{z}, 253$ and $\mathrm{m} / \mathrm{z}, 217$ were found due to the loss of the $-\mathrm{CH}_{3}$ group and $-\mathrm{Cl}$ from the molecular ion.

A standard mix containing 16 phenolic compounds (2,4-DNP; phenol; 2-cresol; 3-cresol; 2-CP; 2,4-xylenol; 4-C-3-MP; 2,6-DCP; 2,4-DCP; 2,5-DCP; 2,4,6-TCP; 2,4,5-ТCP; 2,3,5,6-ТеCP; 2,3,4,6-ТеCP; 2,3,4,5-ТеСР; PCP) was used to validate the library. All 16 phenolic compounds were identified accurately and the match ratios were more than $90 \%$, except for 2,4,5-TCP (73\%), showing that identifying phenolic compounds by the library was reliable.

\subsection{Methods for qualification and quantification}

Even though GC-MS is the most commonly used technique to separate and identify organic chemicals, it is difficult to obtain separation for some phenolic compounds, such as 2,5-DCP and 2,6-DCP, 2,4,6-TCP and 2,3,5-TCP; 4-NP and 2,3,5-TCP [11,16]. Banerjee et al. [17] optimized the oven temperature, ion source temperature, modulation period, duration of hot pulses, modulation-offset temperature, and acquisition rate, etc. to achieve the best possible separation of test compounds. The performance, however, was not satisfactory for a large number of target compounds. Heberer and Stan [11] obtained a good separation through changing chromatographic columns. However, they could not separate all phenolic compounds on the same chromatographic column and their approach consumes both time and money. Moreover, it is not a good choice for obtaining a high resolution. Simultaneously, full scan chromatograms 
Table 1 Compound name, retention time, target ion, quota ion and abundance ratio of ion of each target phenolic compound

\begin{tabular}{|c|c|c|c|c|c|c|c|c|}
\hline Name & R.T. ${ }^{\text {a) }}$ & T.I. ${ }^{\text {b) }}$ & $\mathrm{q} 1^{\mathrm{c})}$ & q1ratio $^{\text {d) }}$ & $\mathrm{q}^{2 \mathrm{e})}$ & q2ratio $^{\mathrm{f}}$ & $q 3^{g)}$ & q33ratio ${ }^{\text {h) }}$ \\
\hline 2,4-Dinitrophenol (2,4-DNP) & 5.958 & 256 & 241 & 127.6 & 191 & 500 & 77 & 346.8 \\
\hline Phenol & 7.809 & 166 & 166 & 100 & 151 & 390.9 & 77 & 49.5 \\
\hline 2-Cresol & 9.100 & 180 & 165 & 183.5 & 149 & 25.6 & 91 & 141 \\
\hline 3-Cresol & 9.277 & 180 & 165 & 272.9 & 149 & 14.8 & 91 & 53.1 \\
\hline 4-Cresol & 9.434 & 180 & 165 & 273.6 & 149 & 15 & 91 & 43.3 \\
\hline 2-Chlororphenol (2-CP) & 10.307 & 200 & 185 & 258.4 & 149 & 256.5 & 93 & 247.2 \\
\hline 2,4-Xylenol & 10.630 & 194 & 179 & 106.2 & 149 & 35.6 & 105 & 78.5 \\
\hline 4-Chlorophenol (4-CP) & 10.733 & 200 & 185 & 266.1 & 149 & 10.2 & 93 & 30.3 \\
\hline 2,6-Xylenol & 10.760 & 194 & 179 & 100.7 & 149 & 42.8 & 105 & 99 \\
\hline 2-Isopropylphenol & 10.825 & 208 & 193 & 297.6 & 151 & 41.4 & 77 & 46.8 \\
\hline 2-Sec-butylphenol & 11.904 & 222 & 193 & 499.3 & 149 & 31.6 & 77 & 74.5 \\
\hline Pyrocatechol & 12.009 & 254 & 239 & 19.9 & 166 & 36.7 & 151 & 38.7 \\
\hline 4-Chloro-3-methylphenol(4-C-3-MP) & 12.096 & 214 & 199 & 188.7 & 149 & 11.3 & 77 & 24.6 \\
\hline 2,5-Dichlorophenol (2,5-DCP) & 12.401 & 234 & 219 & 333.6 & 183 & 17.1 & 93 & 287.4 \\
\hline 2,6-Dichlorophenol (2,6-DCP) & 12.463 & 234 & 219 & 258.1 & 183 & 121.3 & 93 & 96.8 \\
\hline 2,3,6-Trimethylphenol (2,3,6-TMP) & 12.467 & 208 & 193 & 113.3 & 119 & 88.2 & 77 & 30.1 \\
\hline 2,4-Dichlorophenol (2,4-DCP) & 12.693 & 234 & 219 & 297.9 & 183 & 72.3 & 93 & 240.1 \\
\hline Resorcinol & 12.927 & 254 & 239 & 151.6 & 166 & 4.2 & 91 & 8.8 \\
\hline 2,6-Diisopropylphenol & 13.159 & 250 & 235 & 261.6 & 177 & 6.1 & 91 & 16.4 \\
\hline 2-Nitrophenol (2-NP) & 13.213 & 196 & 196 & 100 & 151 & 26.7 & 79 & 31.9 \\
\hline Hydroquinone & 13.274 & 254 & 254 & 100 & 239 & 215.2 & 79 & 148 \\
\hline 3,5-Dimethyl-4-chlorophenol (PCMX) & 13.314 & 228 & 213 & 164.5 & 93 & 25.5 & 77 & 29 \\
\hline 3,5,6-Trichloro-2-pyridinol & 13.798 & 271 & 256 & 713.2 & 234 & 42.5 & 93 & 511.7 \\
\hline 2,4,6-Trichlorophenol (2,4,6-TCP) & 14.335 & 268 & 253 & 534.8 & 217 & 175.3 & 93 & 214.2 \\
\hline 6-Chlorothymol & 14.452 & 256 & 45 & 214.3 & 183 & 10.5 & 77 & 24.1 \\
\hline 4-Nitrophenol (4-NP) & 14.558 & 211 & 211 & 100 & 196 & 392.2 & 150 & 63.1 \\
\hline 2,3,5-Trichlorophenol(2,3,5-TCP) & 14.567 & 270 & 270 & 100 & 253 & 393.3 & 93 & 507.2 \\
\hline 2,4,5-Trichlorophenol (2,4,5-TCP) & 14.688 & 270 & 255 & 333 & 196 & 145.2 & 93 & 352.4 \\
\hline 2,3,6-Trichlorophenol (2,3,6-TCP) & 14.768 & 268 & 268 & 100 & 253 & 522.5 & 93 & 341.2 \\
\hline 4-Chlororesorcinol & 14.851 & 288 & 288 & 100 & 273 & 85 & 93 & 37.4 \\
\hline 4-Chloro-2-nitrophenol (4-C-2-NP) & 14.917 & 230 & 230 & 100 & 77 & 20.8 & 0 & 0 \\
\hline 2-Chlorohydroquinone & 14.955 & 288 & 288 & 100 & 257 & 55.1 & 93 & 35.3 \\
\hline 3,4,5-Trichlorophenol (3,4,5-TCP) & 15.181 & 268 & 268 & 100 & 253 & 225.9 & 93 & 77.7 \\
\hline 2-Naphthol & 15.324 & 216 & 201 & 129.5 & 185 & 12.4 & 127 & 21.8 \\
\hline 2-Biphenylol & 15.768 & 242 & 227 & 145.5 & 211 & 196.2 & 77 & 12.7 \\
\hline 2-Chloro-4-nitrophenol (2-C-4-NP) & 15.994 & 230 & 230 & 100 & 147 & 26.1 & 93 & 54.5 \\
\hline 2,3,5,6-Tetrachlorophenol(2,3,5,6-TeCP) & 16.62 & 304 & 304 & 100 & 289 & 549 & 93 & 337.3 \\
\hline 2,3,4,6-Tetrachlorophenol(2,3,4,6-TeCP) & 16.746 & 304 & 304 & 100 & 289 & 443.6 & 93 & 208.2 \\
\hline 2,3,4,5-Tetrachlorophenol(2,3,4,5-TeCP) & 17.058 & 304 & 304 & 100 & 289 & 418 & 93 & 455.4 \\
\hline 2,4-Dichloro-3-ethyl-6-nitrophenol & 18.181 & 292 & 292 & 100 & 247 & 25.5 & 93 & 12.8 \\
\hline Pentachlorophenol (PCP) & 18.883 & 338 & 338 & 100 & 323 & 504.4 & 93 & 328 \\
\hline Ortho-benzyl-para-chlorophenol & 19.337 & 290 & 290 & 100 & 275 & 94.2 & 181 & 14.9 \\
\hline 2-Chloro-4-phenylphenol & 19.539 & 276 & 261 & 60 & 225 & 146.9 & 93 & 89 \\
\hline Tetrachlorohydroquinone & 19.985 & 392 & 392 & 100 & 375 & 110 & 93 & 138.5 \\
\hline 4,4'-Biphenyldiol & 21.725 & 330 & 330 & 100 & 315 & 13.2 & 150 & 7.4 \\
\hline Biphenol A (BPA) & 22.250 & 357 & 357 & 100 & 372 & 11.2 & 0 & 0 \\
\hline Dichlorophene & 23.207 & 412 & 412 & 100 & 377 & 82.9 & 0 & 0 \\
\hline Hexanoestrol & 23.542 & 399 & 399 & 100 & 179 & 485.9 & 151 & 138.1 \\
\hline Bithionol & 25.636 & 500 & 500 & 100 & 395 & 56.7 & 93 & 37.3 \\
\hline Hexachlorophene & 27.47 & 550 & 550 & 100 & 515 & 226.3 & 208 & 532.2 \\
\hline
\end{tabular}

a ) Retention time. b) Target ion. c) First qualitative ion. d) Abundance of q1/abundance of target ion $\times 100$. e) Second qualitative ion. f) Abundance of q2/abundance of target ion $\times 100$. g) Third qualitative ion. h) Abundance of q3/abundance of target ion $\times 100$.

obtained in our study (such as Figure 1(a)) are overloaded with matrix component peaks, making data evaluation difficult and time consuming. Matrix effect, a serious interference, could not be effectively eliminated or reduced by changing GC-MS conditions or chromatographic columns. 


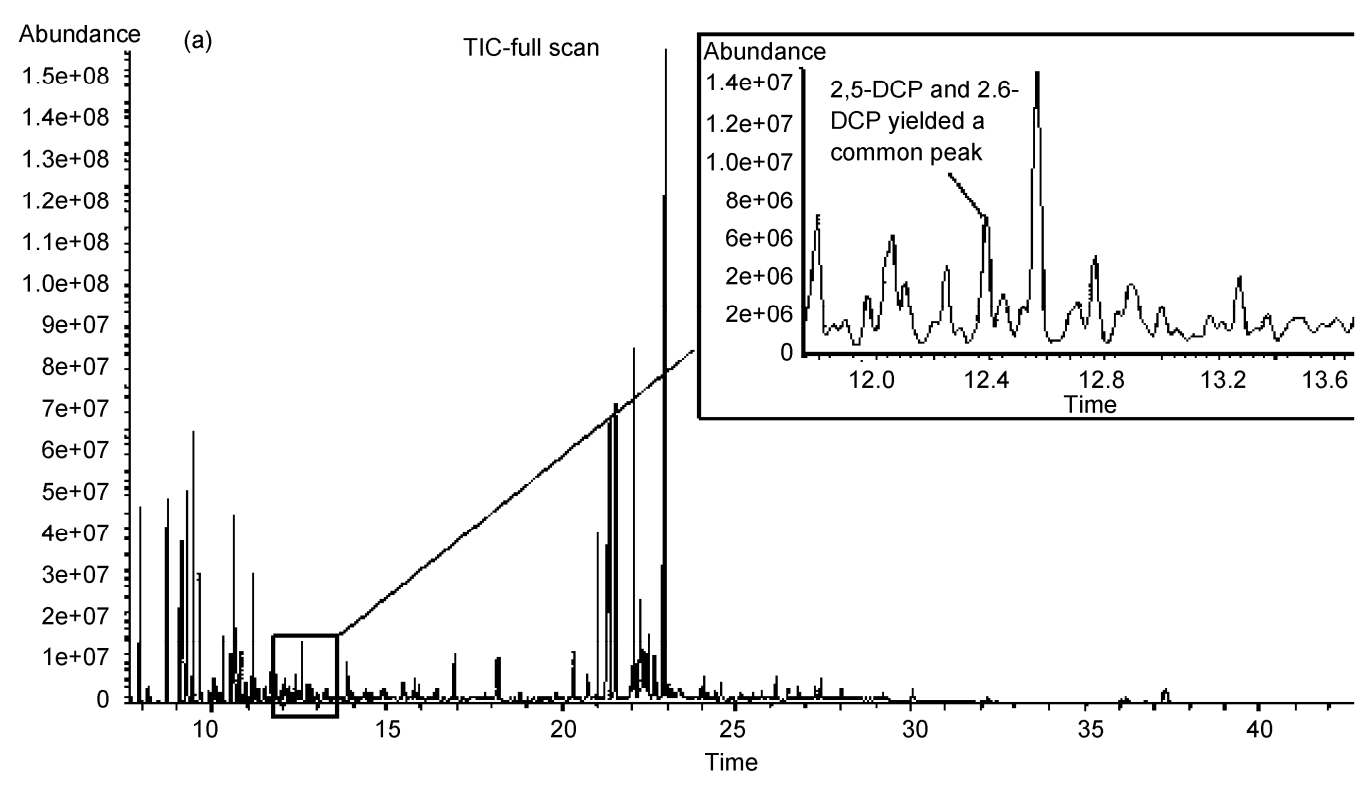

(b)

\begin{tabular}{|c|c|c|c|c|c|c|c|}
\hline \multirow[b]{2}{*}{ R.T. } & \multirow[b]{2}{*}{ Cas\# } & \multirow[b]{2}{*}{ Compound name } & \multirow{2}{*}{$\begin{array}{l}\text { Agilent } \\
\text { Chem station } \\
\text { amount (ng) }\end{array}$} & \multirow{2}{*}{$\frac{\text { AMDIS }}{\text { Match }}$} & \multicolumn{3}{|c|}{ NIST } \\
\hline & & & & & $\begin{array}{l}\text { R.T. Diff } \\
\text { sec }\end{array}$ & $\begin{array}{l}\text { Reverse } \\
\text { match }\end{array}$ & Hit Num. \\
\hline 7. 8560 & 108952 & Phenol & & 85 & 3.2 & & \\
\hline 9.0884 & 95487 & 2-Melhylphenol & & 94 & -0.1 & & \\
\hline 9.2630 & 108394 & 3-Methylphenol & & 88 & -0.8 & & \\
\hline 10.7385 & 106489 & Para-chlorophenol & & 84 & 0.2 & & \\
\hline 12.3909 & 87650 & 2,6-Dichlorophenol & & 79 & -4.5 & & \\
\hline 12.3930 & 583768 & 2,5-Dichlorophenol & & 92 & -0.6 & & \\
\hline 12.4515 & 2416945 & 2,3,6-Trimethylphenol & & 84 & -1.1 & & \\
\hline 15.7308 & 90437 & 2-BIphenylol & & 81 & -3.4 & & \\
\hline
\end{tabular}

Figure 1 (a) Total ion chromatogram of a wastewater sample; (b) DRS report from the analysis of the wastewater sample. From (a), we can find that 2,6-DCP and 2,5-DCP could not be separated absolutely. From (b), we can find that 2,6-DCP and 2,5-DCP could be identified simultaneously using the DRS report. The results of (a) and (b) describe the same wastewater sample.

In this study, RTL, spectral deconvolution and DRS were developed to identify target compounds in GC-MS analysis. Based on the retention times, quota ions and abundance ratio of ions, deconvolution technology could separate and identify chemicals accurately and quickly, even when chemicals were covered by complex matrix elements. For example, 2,5-DCP and 2,6-DCP could be identified simultaneously in the wastewater sample (Figure 1(b)) using DRS and RTL. Therefore, the method developed using RTL and DRS is a good choice for identifying a large number of phenolic compounds in wastewater.

\subsection{Methods for sample preparation}

Phenolic compounds were at trace or low concentration levels in the water samples, so one of the most important requirements is to find a suitable sample preparation technique that allows the separation of phenolic compounds from the sample matrix [18]. Development of SPE proce- dures, which are able to enrich water with quantitative recoveries for priority phenolic compounds, remains an elusive goal. Therefore, procedures for sample preparation to screen phenolic compounds in water were also optimized in this study. The extraction and elution efficiencies of target compounds from water samples were assessed using different types of SPE cartridges and elution solvents. 12 phenolic compounds including phenol, 2-cresol, 3-cresol, 4-cre-sol, 2-CP, 2,6-DCP, 2,4-DCP, 2-NP, 2,4,6-TCP, 2,4,5-TCP, 2,3,4,6-TeCP and PCP were selected as target compounds to optimize the pretreatment procedures. Polarity is an important factor for extraction efficiency [19]. The $\log K_{\text {ow }}$ values of 12 phenolic compounds ranged from 1.5 to 5.07, which covered the polar range of the 50 phenolic compounds [20]. In addition, the mass spectral fragment pathways were also considered. $-\mathrm{CH}_{3},-\mathrm{NO}_{2}$ and $-\mathrm{Cl}$ are the three kinds of substituent groups that are easy to fragment from silylated phenolic compounds, so methylphenol, nitrophenol and chlorophenol were included in the 12 typical 
phenolic compounds. Furthermore, substituent positions and substituent number also were considered in the selection of target phenolic compounds which were then used to optimize the procedures for sample preparation. Therefore, these 12 typical phenolic compounds were representative of the 50 phenolic compounds for polarity, substituent groups, substituent positions and substituent number.

(1) Extraction recovery with various cartridges. Among the many kinds of SPE cartridges available, C18 cartridge and HLB cartridges are the top two most commonly used to pre-concentrate environmental samples. Furthermore, the C18 and HLB cartridges are less selective and retain more compounds, relatively, and they are most commonly used to analyze broad-spectrum compounds. Based on the above considerations, C18 and HLB cartridges with dichloromethane as elution solvent were used in the present investigation (Figure 2). Each method was performed in triplicate. All of the relative standard deviation (RSD\%) values were lower than $7.2 \%$. SPE is very often used in the sample preparation step of the chromatographic analysis of phenolic compounds [21] due to its advantages in trace element determination, namely conservation of species and good pre-concentration factors, enabling the achievement of very low limit of detection [22]. The SPE cartridge is of primary importance in the extraction of target compounds from water samples [23]. The results have shown that $\mathrm{C} 18$ cartridges can strongly retain nonpolar phenolic compounds, compared with HLB cartridges (Figure 2). The recoveries of phenol, cresols, $2-\mathrm{CP}$ and $2-\mathrm{NP}\left(\log K_{\mathrm{ow}}<2\right)$ from the $\mathrm{C} 18$ cartridge were lower than the recoveries of tri-, tetra- and pentachlorophenol, because phenol, cresols, 2-CP and 2-NP are hydrophilic compounds with lower affinity for nonpolar sorbents and low breakthrough volumes in comparison with tri-, tetra- and pentachlorophenol [19]. On the other hand, for HLB cartridges, the recoveries of nonpolar compounds were low. The objective of this study was to screen all the phenolic compounds in the library; therefore, using only one kind of SPE cartridge to enrich samples was unreasonable. The C18 and HLB cartridges could offset the defects of one another so the C18 cartridge coupled with the HLB cartridge was chosen for further experiments.

(2) Elution by different solvents. The recovery of organic compounds by SPE is highly dependent on the polarity of the elution solvent [12]. Twelve different solvents (Table

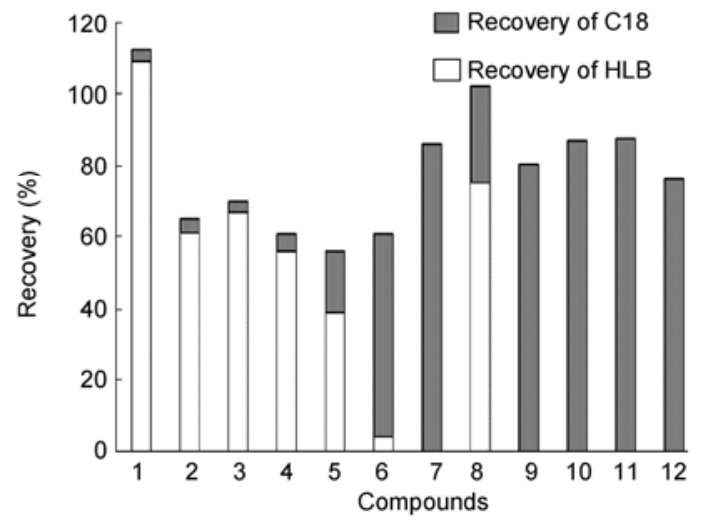

Figure 2 Recoveries of different SPE cartridges. Numbers 1 to 12 represent phenol, 2-cresol, 3-cresol, 4-cresol, 2-CP, 2,6-DCP, 2,4-DCP, 2-NP, 2,4,6-TCP, 2,4,5-TCP, 2,3,4,6-TeCP and PCP, respectively.

2) were tested for the elution recovery of 12 phenolic compounds. The cartridges were eluted with $10 \mathrm{~mL}$ of different solvents. For example, for method 1, the cartridges were first eluted with $10 \mathrm{~mL}$ of mixed solvent of hexane and $\operatorname{DCM}(1: 9, \mathrm{~V}: \mathrm{V})$ and then eluted with $10 \mathrm{~mL}$ of mixed solvent of DCM and methanol $(9: 1, \mathrm{~V}: \mathrm{V})$. Each method was performed in triplicate. All RSD\% values were lower than $13.6 \%$. It can be seen from the results (Figure 3) that DCM produced the best recovery for most of the phenolic compounds $(95.78 \% \pm 26.44 \%)$. Methods 1 and 2 provided poor recovery for all target compounds. A possible reason is that the lower polarity of the elution solvent led to a lower elution ability of polar target compounds [23]. Phenolic compounds have different behavior in terms of acidity and polarity [19]. The purpose of this study was to screen phenolic compounds in water and the polarity range of target compounds was wide. By comprehensive consideration of various factors, dichloromethane was selected as the elution solvent.

\subsection{Quality assurance/quality control (QA/QC)}

Instrumental calibration curves were established from standard solutions with seven concentrations ranging between 50 and $1000 \mu \mathrm{g} \mathrm{L}^{-1}$. The instrument limit of quantification (LOQ) was determined as the analyte mass corresponding to a signal/noise ratio of 10 . The LOQs ranged 0.7 to $87.7 \mathrm{pg}$

Table 2 Proportion schemes of elution solvents

\begin{tabular}{|c|c|c|c|c|c|}
\hline Method & Solvent & Method & Solvent & Method & Solvent \\
\hline 1 & $\begin{array}{l}\text { Hexane:DCM=1:9 } \\
\text { DCM:methanol=9:1 }\end{array}$ & 5 & $\begin{array}{l}\text { Hexane: } \mathrm{DCM}=7: 3 \\
\mathrm{DCM}: \text { methanol=4:1 }\end{array}$ & 9 & $\begin{array}{l}\text { Hexane: } \mathrm{DCM}=1: 1 \\
\mathrm{DCM}: \text { methanol=1:1 }\end{array}$ \\
\hline 2 & $\begin{array}{l}\text { Hexane: } \mathrm{DCM}=7: 3 \\
\text { DCM }: \text { methanol=9: } 1\end{array}$ & 6 & $\begin{array}{l}\text { Hexane: } \mathrm{DCM}=1: 1 \\
\text { DCM:methanol=4:1 }\end{array}$ & 10 & MTBE: methanol $=9: 1$ \\
\hline 3 & $\begin{array}{l}\text { Hexane: } \mathrm{DCM}=1: 1 \\
\text { DCM }: \text { methanol=9:1 }\end{array}$ & 7 & $\begin{array}{l}\text { Hexane: } \mathrm{DCM}=1: 9 \\
\text { DCM:methanol=1:1 }\end{array}$ & 11 & Acetone \\
\hline
\end{tabular}




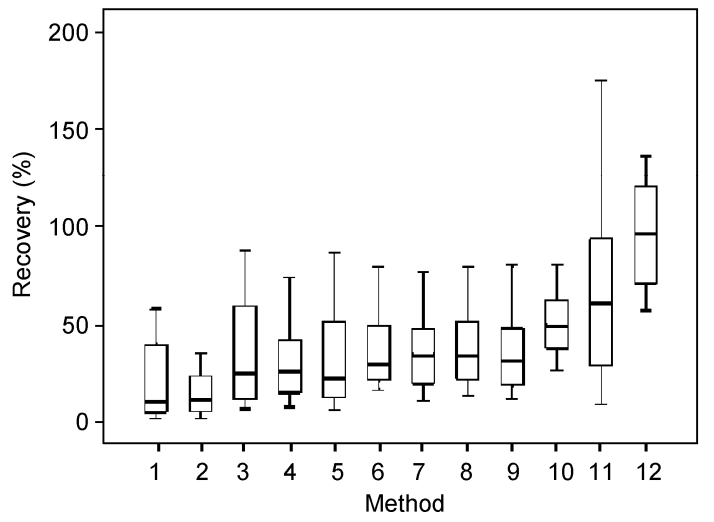

Figure 3 Recoveries using different elution solvents (box plot). Numbers 1 to 12 represent methods 1 to 12 . (injected) for individual phenolic compounds (Table 3). The calibration curve was linear in the entire range $\left(R^{2}\right.$ $=0.995-1.000)$ (Table 4). Matrix-matched calibration curves are listed in Table 4. To further validate the precision and accuracy of the method, blank, matrix spiked and parallel experiments were carried out. Verification experiments were carried out using the 12 typical phenolic compounds selected to optimize the procedures for sample preparation. Seven replicate samples $\left(2 \mathrm{ng} \mathrm{L}^{-1}\right)$, concentrated 4000 times were analyzed using the entire analytical method to calculate method detection limits (MDLs). The MDLs of 12 phenolic compounds ranged from 3.56 to $97.64 \mathrm{ng} \mathrm{L}^{-1}$ (Table 4). No phenolic compound was detected in the blank samples. The matrix spike recoveries for 12 phenolic compounds ranged from $47.87 \%$ to $114.8 \%$ (Table 4 ). The RSD\% values

Table 3 Instrument LOQs of 50 phenolic compounds (pg)

\begin{tabular}{|c|c|c|c|c|c|}
\hline Compound & LOQ & Compound & LOQ & Compound & LOQ \\
\hline 2,4-DNP & 10.0 & Resorcinol & 4.6 & 2-Biphenylol & 13.3 \\
\hline Phenol & 1.5 & Pyrocatechol & 3.2 & 2,6-Diisopropylphenol & 10.0 \\
\hline 2-Cresol & 1.1 & Hydroquinone & 3.3 & 3,5,6-Trichloro-2-pyridinol & 87.7 \\
\hline 3-Cresol & 2.4 & 6-Chlorothymol & 1.4 & 2-Chlorohydroquinone & 4.3 \\
\hline 4-Cresol & 2.5 & PCMX & 5.8 & 2-Isopropylphenol & 5.1 \\
\hline 2-CP & 0.8 & $2,4,6-\mathrm{TCP}$ & 8.9 & 2,4-Dichloro-3-ethyl-6-nitrophenol & 2.4 \\
\hline 2,4- Xylenol & 3.1 & $2,3,5-\mathrm{TCP}$ & 32.9 & 2-Sec-butylphenol & 4.9 \\
\hline 4-CP & 6.2 & $2,4,5-\mathrm{TCP}$ & 9.0 & Ortho-benzyl-para-chlorophenol & 0.9 \\
\hline 2,6-Xylenol & 4.9 & 2,3,6-TCP & 9.0 & 2-Chloro-4-phenylphenol & 2.0 \\
\hline 2-NP & 2.6 & 2,3,5,6-ТeCP & 1.4 & Tetrachlorohydroquinone & 10.0 \\
\hline $4-\mathrm{NP}$ & 0.9 & 2,3,4,6-ТeCP & 2.1 & 4,4'-Biphenyldiol & 9.2 \\
\hline PCP & 1.4 & 2,3,4,5-ТеCP & 1.9 & $\mathrm{BPA}$ & 0.9 \\
\hline 2,5-DCP & 10.9 & 4-C-2-NP & 10.0 & Hexanoestrol & 71.4 \\
\hline $2,6-\mathrm{DCP}$ & 6.2 & $2-\mathrm{C}-4-\mathrm{NP}$ & 6.1 & Bithionol & 55.6 \\
\hline 2,3,6-TMP & 7.3 & $3,4,5-\mathrm{TCP}$ & 1.4 & Hexachlorophene & 10.0 \\
\hline 2,4-DCP & 4.6 & 2-Naphthol & 0.7 & & \\
\hline
\end{tabular}

Table 4 MDLs and Matrix spike recoveries of 12 phenolic compounds

\begin{tabular}{|c|c|c|c|c|}
\hline Compound & MDLs $\left(\right.$ ng L $\left.^{-1}\right)$ & Matrix spike recoveries (\%) & Calibration curves & $R^{2}$ \\
\hline Phenol & 3.56 & 58.06 & $Y=1.641 x+0.0053$ & 1.000 \\
\hline 2-Cresol & 29.73 & 78.12 & $Y=0.52 x+0.0173$ & 0.996 \\
\hline 3-Cresol & 22.84 & 74.64 & $Y=1.559 x-0.1403$ & 0.999 \\
\hline 4-Cresol & 18.42 & 47.87 & $Y=1.625 x-0.1566$ & 0.999 \\
\hline 2-CP & 26.98 & 114.80 & $Y=0.5757 x+0.0036$ & 0.999 \\
\hline 2,4-DCP & 18.55 & 78.34 & $Y=0.4595 x-0.0669$ & 1.000 \\
\hline 2-NP & 97.64 & 56.80 & $Y=0.2173 x-0.0193$ & 0.997 \\
\hline $2,4,6-\mathrm{TCP}$ & 44.54 & 55.97 & $Y=0.4066 x-0.0948$ & 0.997 \\
\hline $2,4,5-\mathrm{TCP}$ & 36.86 & 84.88 & $Y=0.4478 x-0.0872$ & 0.995 \\
\hline 2,3,4,6-ТеСР & 33.43 & 81.73 & $Y=0.4014 x-0.1090$ & 0.997 \\
\hline
\end{tabular}


for all recovery experiments were lower than $13.6 \%$, showing that the precision of this method is excellent.

\subsection{Application of the method to real samples}

Tianjin is located in northern China near Beijing, adjacent to the Bohai Sea, and it is the third largest industrial center in China. On average, the industries in those areas discharge about 180 million tons of wastewater annually. Confronted with water shortages in agriculture, wastewater irrigation has been commonly practiced in this area for more than 40 years [24]. Rivers in the Tianjin area are severely polluted with high loads of persistent organic pollutants [25] and these bring risks to the water environment. It is important and urgent, therefore, to evaluate the removal efficiency of pollutants in STPs in Tianjin, China.

(1) Identification of phenolic compounds in wastewater. The identification and quantification method was applied to analyze samples from five STPs located in Tianjin, China. All samples were analyzed by DRS: the match values were more than $80 \%$ and retention time difference between the database and observed values were less than 5 seconds. Identification of phenolic compounds in samples taken at different STPs indicates that phenolic compounds were widely present in wastewater. Different phenolic compounds were identified in different STPs (Table 5) and most were identified as un-regulated phenolic compounds. Although many kinds of phenolic compounds existed in influents (2-cresol, 3-cresol, 4-cresol, 4-CP, 2,4-DCP, 2,6-DCP, 2,3,6-TMP, 2-sec-butylphenol, PCMX, 2-napthol, 6-chlorothymol and 2-phenylphenol), only few existed in effluents, indicating that treatment processes in STPs could have removed the 12 phenolic compounds effectively. Among the phenolic compounds identified in effluent, phenol and 2,4,6-TCP belong to the regulated phenolic compounds; 2-CP, 2,5-DCP and 2,4-dichloro-3-ethyl-6nitro-phenol belong to the un-regulated phenolic compounds. 2-CP and 2,4,6-TCP are classified as priority pollutants by the United States Environmental Protection Agency (US EPA) [26]. 2,5-DCP has been used as a biomarker of exposure to 1,4-dichlorobenzene (1,4-DCB) [27]. Furthermore, it is been assumed that 2,5-DCP may have a key function in 1,4-DCB induced genotoxicity [28]. There is insufficient data available about the harm caused by 2,4-dichloro-3-ethyl-6-nitrophenol. Therefore, the occurrence of the phenolic compounds in wastewater should be given more attention.

(2) Quantitative analysis of wastewater. The quantitative results are shown in Table 5. The surrogate recoveries of all samples ranged from $67.4 \%$ to $108.7 \%$. For the total phenolic compounds, the removal efficiencies were $99.97 \%$ for STP1, $99.95 \%$ for STP2, $88.95 \%$ for STP3, $98.04 \%$ for STP4 and $99.51 \%$ for STP5.

Phenolic compounds were identified in all the effluents of the STPs. The highest concentration occurred in STP4 $\left(0.98 \mu \mathrm{g} \mathrm{L}^{-1}\right)$. The concentrations of 2,4,6-TCP in the effluents from STP2, STP3, STP4 and STP5 were 0.07, 0.16, 0.25 and $0.10 \mu \mathrm{g} \mathrm{L}^{-1}$, respectively. Phenol and 2,4,6-TCP belong to regulated phenolic compounds, and their concentrations met the discharge standard of pollutants for municipal wastewater treatment plants, China [29].

2-CP was identified in the influent of all the STPs and in the effluents of STP1 and STP4. The concentrations of 2-CP in effluents were 0.14 and $0.12 \mu \mathrm{g} \mathrm{L}{ }^{-1}$ for STP1 and STP4, respectively. There is no relevant standard for $2-\mathrm{CP}$ in China but it has been classed as a priority pollutant by the US EPA [26]. As reported by the US EPA [30], the threshold

Table 5 Qualitative and quantitative results of wastewater samples $\left(\mu \mathrm{g} \mathrm{L}^{-1}\right)$

\begin{tabular}{|c|c|c|c|c|c|c|c|c|c|c|}
\hline \multirow{2}{*}{ Compound } & \multicolumn{2}{|c|}{ STP1 } & \multicolumn{2}{|c|}{ STP2 } & \multicolumn{2}{|c|}{ STP3 } & \multicolumn{2}{|c|}{ STP4 } & \multicolumn{2}{|c|}{ STP5 } \\
\hline & STP1A & STP1B & STP2A & STP2B & STP3A & STP3B & STP4A & STP4B & STP5A & STP5B \\
\hline Phenol & 34.6 & 0.05 & - & 0.27 & - & 0.52 & 0.58 & 0.98 & 16.9 & 0.12 \\
\hline 2-Cresol & 16.5 & - & 23.1 & - & 16.2 & - & 25.8 & - & 4.4 & - \\
\hline 3-Cresol & 19.0 & - & 31 & - & 15.8 & - & 19.1 & - & 4.07 & - \\
\hline 4-Cresol & 18.2 & - & 29.7 & - & 15.1 & - & 18.3 & - & 3.9 & - \\
\hline 2-CP & 32.8 & 0.14 & 101 & - & 17.3 & - & 24.5 & 0.12 & 10.6 & - \\
\hline 4-CP & - & - & - & - & 0.7 & - & 13.2 & - & - & - \\
\hline 2,6-DCP & - & - & - & - & 28.4 & - & - & - & 0.98 & - \\
\hline 2,4-DCP & - & - & - & - & 30.7 & - & - & - & - & - \\
\hline $2,5-\mathrm{DCP}$ & 30.2 & - & 1.66 & - & 41.8 & - & 0.31 & 1.89 & 1.42 & - \\
\hline $2,4,6-\mathrm{TCP}$ & - & - & 0.36 & 0.07 & - & 0.16 & - & 0.25 & 0.57 & 0.1 \\
\hline 2,3,6-TMP & - & - & - & - & 2.3 & - & - & - & 0.36 & - \\
\hline 2-Sec-butylphenol & 210 & - & 348 & - & 12.4 & - & 55.8 & - & - & - \\
\hline PCMX & 404 & - & 16.2 & - & 3.68 & - & 7.29 & - & - & - \\
\hline 6-Chlorothymol & - & - & 0.19 & - & 0.13 & - & - & - & 1.11 & - \\
\hline 2,4-Dichloro-3-ethyl-6-nitrophenol & - & - & - & - & 22.2 & 22.6 & - & - & - & - \\
\hline 2-Phenylphenol & 7.66 & - & - & - & 0.18 & - & - & - & 0.1 & - \\
\hline
\end{tabular}


level of 2-chlorophenol in water that causes tainting in eel flesh and oysters is $0.125 \mu \mathrm{g} \mathrm{L^{-1 }}$ and the odor threshold concentration is $0.1 \mu \mathrm{g} \mathrm{L}^{-1}$. The occurrence of 2-CP should be given more attention.

2,5-DCP was identified only in the effluent of STP4 and is noteworthy as the content in the effluent $\left(1.89 \mu \mathrm{g} \mathrm{L}^{-1}\right)$ was much higher than in the influent water $\left(0.31 \mu \mathrm{g} \mathrm{L}^{-1}\right)$. This result indicates that 2,5-DCP must have been introduced during the hydrolysis acidification-biological filter process. The concentration of 2,5-DCP in the effluent of STP4 exceeds the odor threshold concentration $\left(0.5 \mu \mathrm{g} \mathrm{L}^{-1}\right)$ proposed by the US EPA [30]. 2,5-DCP has also been classified as a strongly toxic material by a PBT profiler, developed by the Environmental Science Center of the US EPA [31]. The occurrence of 2,5-DCP could cause serious issues.

2,4-dichloro-3-ethyl-6-nitrophenol was only identified in STP3. Furthermore, the conventional active sludge process applied by STP3 could not remove 2,4-dichloro-3-ethyl6-nitrophenol absolutely. 2,4-dichloro-3-ethyl-6-nitrophenol is one of the products of a chemical plant near STP3 so its presence might have been caused by effluent discharge from the chemical plant. 2,4-dichloro-3-ethyl-6-nitrophenol is a benzene series intermediate and has been classified to have strong toxic potential and to be a persistent material by the PBT profiler [31].

In brief, the concentrations of regulated phenolic compounds in the effluents of five STPs met the standard requirements but the occurrence of un-regulated phenolic compounds could cause serious environmental damage and indicates that more attention should be paid to them.

\section{Conclusion}

RTL and DRS were introduced for the first time to identify and quantify phenolic compounds in wastewater. This method allows accurate identification and quantification of phenolic compounds with high sensitivity and could be readily extended to include additional analytes. Furthermore, the method demonstrated, including an optimized preparation procedure, is very simple, fast, and is a viable alternative for routine monitoring of phenolic compounds in water. The results indicate that enriching phenolic compounds by a $\mathrm{C} 18$ cartridge coupled with a HLB cartridge and eluting with DCM is the optimal preparation method (LOQs range 0.7-87.7 pg). Applying the entire analytical method, phenolic compounds can be detected at the $\mathrm{ng} \mathrm{L}^{-1}$ level in environmental samples, independent of the origin of the sample and its matrix load.

The method was successfully applied to analyze wastewater of five STPs. Only a few types of phenolic compound were identified in effluents. The un-regulated phenolic compounds in effluents may cause environmental effects and should be given more attention, although the concentrations of regulated phenolic compounds met the discharge standards of pollutants for municipal wastewater treatment plants in China.

This work was supported by the National Science \& Technology Pillar Program (2007BAC27B02-1b), the National Natural Science Foundation of China (20977102), Important National Science \& Technology Specific Projects (2008ZX07314-003), and a Special Fund from the State Key Laboratory of Environmental Aquatic Chemistry (09Y11ESPCR).

1 Kong X J, Li D, Cao L Q, et al. Evaluation of municipal sewage treatment systems for pollutant removal efficiency by measuring levels of micropollutants. Chemosphere, 2008, 72: 59-66

2 Bielicka-Daszkiewicz K, Dębicka M, Voelkel A. Comparison of three derivatization ways in the separation of 423 phenol and hydroquinone from water samples. J Chromatogr A, 2004, 1052: 233-236

3 Korach K S. Surprising places of estrogenic activity. Endocrinology, 1993, 132: 2277-2278

4 Terasaka S, Inoue A, Tanji M, et al. Expression profiling of estrogen-responsive genes in breast cancer cells treated with alkylphenols, chlorinated phenols, parabens, or bis- and benzoylphenols for evaluation of estrogenic activity. Toxicol Lett, 2006, 163: 130-141

5 WHO (World Health Organization), Environmental health criteria 93. Chlorophenols other than pentachlorophenol, Geneva, 1989

6 Kalliokoski P, Kauppinen T. Complex chlorinated hydrocarbons: occupational exposure in the sawmill industry. IARC Sci Publ, 1990, 104: 390-396

7 Davì M L, Gnudi F. Phenolic compounds in surface water. Water Res, 1999, 33: 3213-3219

8 Kasprzyk-Hordern B, Dinsdale R M, Guwy A J. The removal of pharmaceuticals, personal care products, endocrine disruptors and illicit drugs during wastewater treatment and its impact on the quality of receiving waters. Water Res, 2009, 43: 363-380

9 Nakada N, Shinohara H, Murata A, et al. Removal of selected pharmaceuticals and personal care products (PPCPs) and endocrine-disrupting chemicals (EDCs) during sand filtration and ozonation at a municipal sewage treatment plant. Water Res, 2007, 41: 4373-4382

10 Wang Y Q, Hu W, Cao Z H, et al. Occurrence of endocrine-disrupting compounds in reclaimed water from Tianjin, China. Anal Bioanal Chem, 2005, 383: 857-863

11 Heberer T, Stan H J. Detection of more than 50 substituted phenols as their t-butyldimethylsilyl derivatives using gas chromatography-mass spectrometry. Anal Chim Acta, 1997, 341: 21-34

12 Liu R, Zhou J L, Wilding A, Simultaneous determination of endocrine disrupting phenolic compounds and steroids in water by solid-phase extraction-gas chromatography-mass spectrometry. J Chromatogr A, 2004, 1022: 179-189

13 Wylie P L, Szelewski M J, Meng C K. Comprehensive pesticide screening by GC/MSD using deconvolution reporting software. Agilent Technologies. Application Note (23) 5989-1157E, 2004, Available from: http://www.agilent.com/chem (last accessed February, 2010)

14 Weiner K R, Prest H F. Retention time locking: creating custom retention time locked screener libraries. Agilent Technologies. Application Note (23) 5968-8657E, 1999, Available from: http://www. agilent.com/chem (last accessed February, 2010)

15 Zhou Y Q, Ma M, Wang Z J. Determination of nonylphenols in water by pre-column derivatization and gas chromatography coupled with mass spectrometry. Chinese J Analyt Chem, 2005, 33: 1109-1112

16 Kovócs Á, Kende A, Mörtl M, et al. Determination of phenols and chlorophenols as trimethylsilyl derivatives using gas chromatography-mass spectrometry. J Chromatogr A, 2008, 1194: 139-142

17 Banerjee K, Patil S H, Dasgupta S, et al. Optimization of separation and detection conditions for the multiresidue analysis of pesticides in grapes by comprehensive two-dimensional gas chromatography-timeof-flight mass spectrometry. J Chromatogr A, 2008, 1190: 350-357 
18 Montero L, Conradi S, Weiss H, et al. Determination of phenols in lake and ground water samples by stir bar sorptive extraction-thermal desorption-gas chromatography-mass spectrometry. J Chromatogr A, 2005, 1071: 163-169

19 Rodríguez I, Llompart M P, Cela R. Solid-phase extraction of phenols. J Chromatogr A, 2000, 885: 291-304

20 LOGKOW@. A databank of evaluated octanol-water partition coefficients (LogP), February 2010. Available from: http://logkow.cisti.nrc. ca/logkow/ (last accessed February, 2010)

21 Ge F, Zhu L Z, Wang J. Distribution of chlorination products of phenols under various pHs in water disinfection. Desalination, 2008, 225: 156-166.

22 Mester Z, Sturgeon R. Sample preparation for trace element analysis. 2003. 393-451

23 Wu J M, Hu R K, Yue J Q, et al. Determination of fecal sterols by gas chromatography-mass spectrometry with solid-phase extraction and injection-port derivatization. J Chromatogr A, 2009, 1216: 1053-1058

24 Shi Z, Tao S, Pan B, et al. Contamination of rivers in Tianjin, China by polycyclic aromatic hydrocarbons. Environ Pollut, 2004, 134: 97111
25 Tao S, Cao H Y, Liu W X, et al. Fate modeling of phenanthrene with regional variation in Tianjin, China. Environ Sci Technol, 2003, 37: 2453-2459

26 U.S. EPA (U. S. Environmental Protection Agency). National Recommended Water Quality Criteria, 2005, Available from: http:// www.epa.gov/waterscience/criteria/wqctable/\#priority (last accessed February, 2010)

27 Hill R H, Head S L, Baker S, et al. Pesticide residues in urine of adults living in the United States: Reference Range concentrations. Environ Res, 1995, 71: 99-108

28 Tegethoff K, Herbold B A, Bomhard E M. Investigations on the mutagenicity of 1,4-dichlorobenzene and its main metabolite 2,5-dichlorophenol in vivo and in vitro. Mutat Res, 2000, 470: 161-167

29 Ministry of Environmental Protection of the People's Republic of China. Discharge Standard of Pollutants for Municipal Wastewater Treatment Plant (GB18918-2002), 2002

30 US EPA (United States Environmental Protection Agency). Ambient water quality criteria for chlorinated phenols (EPA 440/5-80-032), 1980

31 US EPA (United States Environmental Protection Agency). Environmental Science Center. PBT profiler, 2006. Available from: http:// www.pbtprofiler.net/Results.asp (last accessed February, 2010)

Open Access This article is distributed under the terms of the Creative Commons Attribution License which permits any use, distribution, and reproduction in any medium, provided the original author(s) and source are credited. 